\title{
Intact emotion-induced recognition bias in neuropsychological patients with executive control deficits
}

\author{
SABINE WINDMANN \\ Johann Wolfgang Goethe University of Frankfurt, Frankfurt, Germany \\ and University of Plymouth, Plymouth, England
}

TILL SCHNEIDER, JULIA RECZIO, and MARTIN GROBOSCH

Ruhr University Bochum, Bochum, Germany

and
VOLKER VOELZKE, VALERIE BLASIUS, ANDREA BRÄMER, WERNER ISCHEBECK, GRAZYNA JANIKOWSKI, WINFRIED MANDRELLA, CLAUDIA UNGER, and LARISSA WISCHNJAK Klinik Holthausen, Hattingen, Germany

\begin{abstract}
In recognition memory tasks, emotionally negative words are judged more often as "old" relative to emotionally neutral words, suggesting a shift in response bias. We wondered whether this bias shift was due to the flexible regulation of executive control during memory retrieval. To address this question, we investigated individuals with high variability in executive control functions. As expected, we observed that emotional word meaning did indeed have a strong influence on the bias toward responding "old," independent of recognition accuracy and overall response bias. However, these effects were uncorrelated with executive control, as measured by the Trail Making Test, and were fully intact, even in a sample of hospitalized neurological patients with severe executive dysfunctions, some of whom had marked damage in fronto-thalamo-striatal networks. Having concluded that the emotion-induced bias must develop on different grounds, we went on to discuss alternative explanations.
\end{abstract}

Emotional arousal can alter and improve encoding and consolidation of long-term memories. A number of neurophysiological mechanisms have been identified that contribute to this process (see, e.g., Dolan, 2002; Maren, 2005; McGaugh, 2003; Phelps, 2004). However, mechanisms that may foster emotional memories at the time of retrieval, when the memory trace can no longer be strengthened, are less well understood at present.

Laboratory studies suggest that relaxing the decision criterion or response bias may be an additional mechanism by which the cognitive system can effectively increase its chances that emotional events are not forgotten or overlooked (Johansson, Mecklinger, \& Treese, 2004; Maratos, Allan, \& Rugg, 2000; McNeely, Dywan, \& Segalowitz, 2004; Windmann, Daum, \& Güntürkün, 2002; Windmann \& Krüger, 1998; Windmann \& Kutas, 2001). Most of these studies have used recognition memory tasks with word stimuli to investigate not only correct recognition but

This work was supported by Grant Wi 1582/2-1 from the German Research Foundation (Deutsche Forschungsgemeinschaft) to S.W. Author listing after the fifth author is in alphabetical order. Correspondence concerning this article should be addressed to S. Windmann, Johann Wolfgang Goethe University of Frankfurt, Institute of Psychology, Mertonstraße 17, 60054 Frankfurt am Main, Germany (e-mail: s.windmann@ psych.uni-frankfurt.de). also false recognition of emotionally negative rather than neutral events. The usual finding is that emotionally negative words are associated with a more liberal bias toward responding "old," resulting in increased hit rates as well as false alarm rates, while making responses faster. This suggests that, although emotionally negative experiences are more easily recognized as parts of the personal past, they are also more often falsely classified as such, due to a transient shift (or relaxation) of the decision criterion employed during memory retrieval. Since this shift is evident not only in old items but also in new items that have not been presented before (by definition of bias), it must result from processes occurring at the time of retrieval, not during consolidation or encoding of the materials.

Studies using event-related potentials (ERPs) have suggested that this emotion-induced recognition bias (EIRB) is correlated with an ERP effect occurring around $400 \mathrm{msec}$ poststimulus, a time frame sensitive to automatic memory effects (Johansson et al., 2004; McNeely et al., 2004; Windmann \& Kutas, 2001). The fact that these effects precede consciously controlled memory retrieval has led to the hypothesis that affect processing might automatically interfere with criterion setting and executive control functions activated early during memory retrieval (Windmann, Urbach, \& Kutas, 2002) and other cognitive tasks. The idea is that emotional arousal inter- 
rupts and impedes ongoing task-related monitoring and control processes, thereby facilitating the fast and more automatically performed responses that are typical for salient and highly familiar stimuli (Bartholow, Dickter, \& Sestir, 2006; Matthews \& Wells, 2000; Newman et al., 2003; Windmann \& Chmielewski, 2006).

The brain structures involved in task monitoring and executive control processes are prefrontal circuits, which operate in concert with other brain regions (e.g., Andrés, 2003; Heyder, Suchan, \& Daum, 2004; Sylvester et al., 2003). During recognition memory, these networks are responsible for criterion setting and postretrieval verification processes (Henson, Rugg, Shallice, \& Dolan, 2000; Miller, Handy, Cutler, Inati, \& Wolford, 2001) and the willful suppression of unwanted or currently irrelevant memories (Anderson et al., 2004; Schnider \& Ptak, 1999). Furthermore, neurons in the ventral part of the prefrontal cortex have very quick access to affective information contained in complex sensory stimuli (Kawasaki et al., 2001). By using this information, the prefrontal cortex, in coordination with the other cortical and subcortical structures mediating executive control (Andrés, 2003; Heyder et al., 2004; Sylvester et al., 2003), is able to quickly and automatically adapt decision biases and impulse control functions (Bechara, Tranel, \& Damasio, 2000; O’Doherty, Critchley, Deichmann, \& Dolan, 2003). The emotion-related shift of the response bias reflected in the EIRB could rely on the functions of this very same system, insofar as criterion setting and executive control functions - normally employed to prevent retrieval of irrelevant memories - might be reduced, adjusted, or otherwise altered under the influence of affective cues to facilitate responding.

To test this hypothesis, we investigated participants across a wide range of executive control functions with an old/new recognition memory test involving emotionally negative and neutral words. Our primary aim was to find out whether the EIRB would depend on intact executive control in the sense of attentional set shifting, the type of control function that could be responsible for the flexible, trial-by-trial shift of the decision criterion observed in the EIRB. In our sample, we included hospitalized patients with severe brain damage in fronto-thalamo-striatal networks with impaired executive control (Andrés, 2003; Heyder et al., 2004), as well as a group of healthy participants. This was done, not with the intention of localizing the relevant cognitive functions in the brain, as is customary in neuropsychological studies, but to obtain a wider variability in executive functions and dysfunctions, so that covariations with the EIRB would be likely to emerge.

We hypothesized that if the EIRB were related to the flexible, affect-dependent adjustment of executively controlled criterion-setting and decision-making processes, it should correlate positively with performance on a standard test of executive control; that is, only individuals with relatively intact executive control functions should be able to normally employ these functions during retrieval of emotionally neutral items while quickly deploying (or relaxing) them during retrieval of emotionally nega- tive items. In contrast, participants with severe executive control deficits should be less able to show this affectdependent, trial-by-trial shift of their decision biases, and should instead employ a relatively rigid decision criterion throughout the entire test session.

As the relevant measure of executive control, we chose the Trail Making Test (TMT; Reitan, 1992), a standardized neuropsychological test requiring participants to shift flexibly, on a trial-by-trial basis, between two different response criteria (numbers and letters) during the execution of a simple visuomotor task. We assumed that this process would reflect the type of cognitive control process that might also be central to the EIRB, where participants frequently shift between a liberal and a more conservative response criterion, depending on the affective meaning of the (randomly presented) test items.

\section{METHOD}

\section{Participants}

There were 52 participants, none of them students, in the study. Twenty-three were patients hospitalized in the Clinic for Neurosurgical Rehabilitation in Hattingen-Holthausen, Germany (Table 1). They were selected for the study by the practicing clinical neuropsychologists on the basis of the executive dysfunctions they showed during routine neuropsychological assessments, mostly because of an estimated percent rank of 10 or less in the Tower of Hanoi task (estimations were based on von Cramon, Matthes-von Cramon, 1991) and failure to perform on the computerized version of the Wisconsin Card Sorting task (CKV; Drühe-Wienholt \& Wienholt, 1998). Many patients had memory dysfunctions in addition to executive deficits. One patient was later excluded from data analysis because she had obviously misunderstood the instructions. The remaining participants were 16 male and 8 female patients with a mean age of 52.95 years (range, 18-77), and 13 healthy men and 16 healthy women with a mean age of 47.82 years (range, 18-79), who were closely matched to the patients in terms of socioeconomic status and levels of education.

\section{Materials}

Two lists containing 30 German nouns each were used (for a translation, see the Appendix), one containing emotionally negative words, the other containing neutral words related to the concept of "academia," to eyesight-match the word lists for semantic cohesiveness and abstractness (but see Results and Discussion). Word length and frequency were controlled using the Cosmas database (www. ids-mannheim.de/kl/projekte/cosmas_1). The two word lists were then divided into two halves, of which one was presented at study, counterbalanced across participants. Words from both lists were presented at test.

We used Forms A and B of the TMT. Form A requires participants to sequentially connect 25 encircled numbers on a page by drawing lines between them with a pencil. Form B requires participants to alternate between numbers and letters when drawing the connecting lines. The attentional set shifting involved in Form B requires executive control, whereas Form A is merely a test of visuomotor functions. The difference in completion times between TMT-B and TMT-A is regarded as an index of executive control (Ble et al., 2005; Drane, Yuspeh, Huthwaite, \& Klingler, 2002).

\section{Procedure}

Participants were asked to take part in a memory test. On a laptop computer screen, they were presented the study words in a large sans-serif font, one at a time in quasirandomized order. Participants were asked to read the words out and rate their emotional valence 
Table 1

Neurological Diagnosis and Executive Dysfunctions of the Patients, As Observed in Tests

\begin{tabular}{|c|c|c|c|}
\hline $\begin{array}{l}\text { Patient } \\
\text { ID No. }\end{array}$ & Neurological Diagnosis & $\begin{array}{l}\text { Tower of Hanoi } \\
\text { Test }\end{array}$ & Other Tests \\
\hline 2 & $\begin{array}{l}\text { Subarachnoid hemorrhage (rupture and clip } \\
\text { of an aneurysm of the anterior communicating artery) } \\
\text { and intracerebral bleeding with left frontal lesions }\end{array}$ & 3 disks, abort & $\begin{array}{l}\text { CKV: concept loss; block design: } \\
\mathrm{WP}=6 \text {; Benton: } \mathrm{PR}=1\end{array}$ \\
\hline 3 & Cerebellar bleeding and infarction with bithalamic lesion & 3 disks, abort & CKV: abort \\
\hline 5 & Traumatic brain injury with small right frontal lesion & & CKV: abort; \\
\hline 6 & $\begin{array}{l}\text { Cerebellar infarction and infarction of the right medial cerebral artery } \\
\text { with cerebellar and right temporal lesions }\end{array}$ & $\begin{array}{l}3 \text { disks, only with } \\
\text { assistance }\end{array}$ & CKV: abort; block design: $\mathrm{WP}=5$ \\
\hline 7 & $\begin{array}{l}\text { Traumatic brain injury with right frontal, left temporal, } \\
\text { and left parietal lesions }\end{array}$ & & CKV: persev. $>42 \%$ \\
\hline 9 & $\begin{array}{l}\text { Aneurysm of the left basilar artery with multiple infarction } \\
\text { and left temporal lesions }\end{array}$ & $\begin{array}{l}3 \text { disks, only with } \\
\text { assistance }\end{array}$ & CKV: abort; Benton: PR $<10$ \\
\hline 10 & $\begin{array}{l}\text { Traumatic subarachnoid hemorrhage with bifrontal } \\
\text { and right temporal lesions }\end{array}$ & 3 disks, abort & CKV: abort \\
\hline 11 & $\begin{array}{l}\text { Subarachnoid hemorrhage (rupture and clip of an aneurysm } \\
\text { of the pericallosal artery) with bifrontal lesions }\end{array}$ & 3 disks, abort & $\begin{array}{l}\text { CKV: abort; block design: } \mathrm{WP}=5 \text {; } \\
\text { Benton: } \mathrm{PR}<10\end{array}$ \\
\hline 12 & $\begin{array}{l}\text { Subarachnoid hemorrhage (rupture and coiling of an aneurysm } \\
\text { of the anterior communicating artery) without focal lesions }\end{array}$ & $\begin{array}{l}\text { very insecure, } \\
\text { fearful }\end{array}$ & \\
\hline 16 & Basal ganglia bleeding with left basal ganglia lesions & $\begin{array}{l}4 \text { disks, only with } \\
\text { assistance }\end{array}$ & CKV: abort; Benton: PR $<10$ \\
\hline 17 & $\begin{array}{l}\text { Subdural bleeding with bifrontal, bitemporal, } \\
\text { and biparietal lesions }\end{array}$ & $\begin{array}{l}3 \text { disks, only with } \\
\text { assistance }\end{array}$ & $\begin{array}{l}\text { CKV: abort; CFT: n.a.; } \\
\text { Benton: PR }<10\end{array}$ \\
\hline 19 & $\begin{array}{l}\text { Intracerebral bleeding with right frontal } \\
\text { and parietal lesions }\end{array}$ & $\begin{array}{l}4 \text { disks, only with } \\
\text { assistance }\end{array}$ & CKV: abort; block design: WP $=3$ \\
\hline 20 & Thalamic bleeding with right thalamic lesions & $\begin{array}{l}4 \text { disks, only with } \\
\text { assistance }\end{array}$ & $\begin{array}{l}\text { CKV: abort; CFT: n.a.; } \\
\text { Benton: PR }<10\end{array}$ \\
\hline 21 & $\begin{array}{l}\text { Subarachnoid hemorrhage (rupture and clip of an aneurysm of the left } \\
\text { pericallosal artery) with bifrontal, left insular, and left parietal lesions }\end{array}$ & & Block design: $\mathrm{WP}=6$ \\
\hline 22 & Thalamic bleeding with left thalamic lesions & & $\begin{array}{l}\text { CKV: abort; block design: } \mathrm{WP}=6 \text {; } \\
\text { Benton: } \mathrm{PR}<10\end{array}$ \\
\hline 23 & Hypoxia without focal lesion & & \\
\hline 24 & $\begin{array}{l}\text { Infarction of the right middle cerebral artery } \\
\text { with lesions of the right basal ganglia and right insular region }\end{array}$ & 3 disks, abort & CKV: abort; block design: $\mathrm{WP}=3$ \\
\hline
\end{tabular}

Note-PR, percent rank; WP, age-normed standard score in the block-design test of the Wechsler Adult Intelligence Scale (Wechsler, 2001); Benton, Word Fluency Test (Benton \& Hamsher, 1989); CKV, computerized version of the modified Wisconsin Card Sorting Test (Drühe-Wienholt \& Wienholt, 1998); CFT, Rey-Osterrieth Complex Figure Test (Sami, Carte, Hinshaw, \& Zupan, 2003; Watanabe et al., 2005); n.a., no adequate performance. 
A

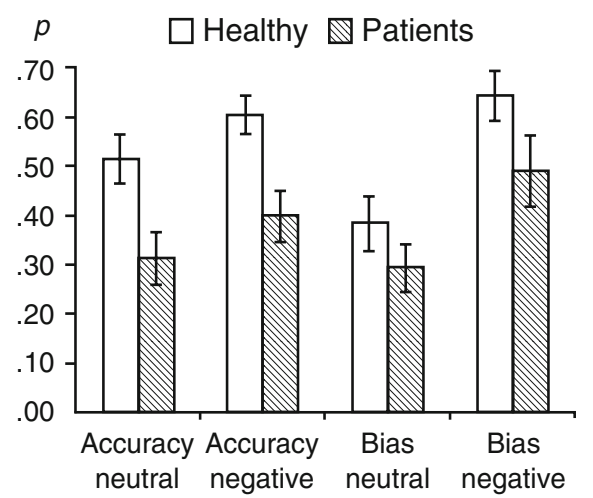

B

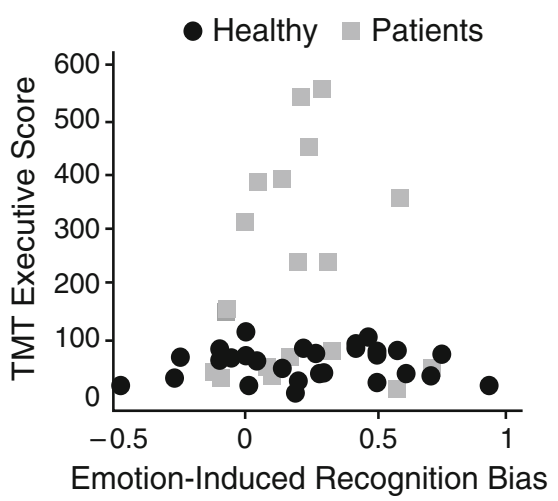

C

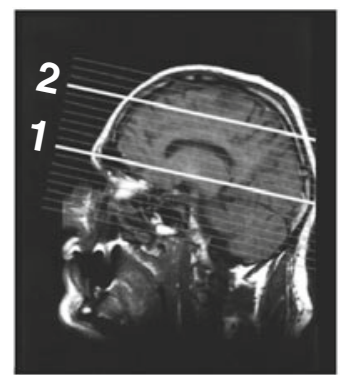

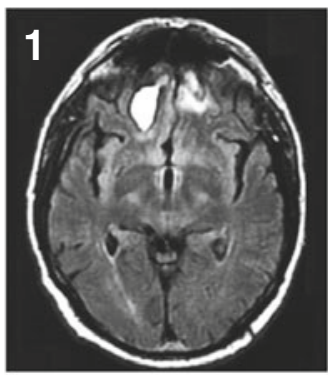

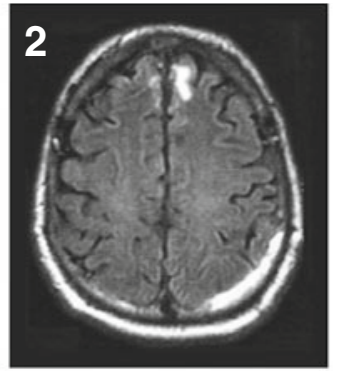

Figure 1. (A) Recognition accuracy and bias of the patients and the healthy participants for the emotionally negative and neutral words. (B) Scatterplot illustrating the absence of correlation between the Trail-Making Test Executive Score and the Emotion-Induced Recognition Bias for the two groups of participants. The correlation was $r=.032$ in the healthy group and $r=.082$ in the patient sample. (C) Single case (patient ID No. 10, a 55-year-old engineer) who suffered traumatic subarachnoidal bleeding leading to bilateral frontopolar and ventromedial ischemic damage, more pronounced in the right hemisphere (middle panel), in addition to dorsomedial lesions (right panel). The left panel shows the slice levels at which the MRT scans were taken. The patient was selected for the study because he displayed excessively perseverative behavior in the Tower of Hanoi task, among other deficits in planning and reasoning - deficits of which he himself was completely unaware. It took him 436 sec to complete the TMT-B, but he had a marked and fully intact emotion-induced bias of .59 (difference in bias between negative and neutral words) in addition to a normal recognition accuracy of $P_{\mathrm{r}}=.50$.

(1: positive; 2 : neutral; 3 : negative). This was done to ensure that all patients understood the emotional meanings of the words.

Thereafter, both forms of the TMT were administered. Four patients failed to complete Form B within a reasonable time, because they were unable to perform the set shifts; their times were set to $600 \mathrm{sec}(10 \mathrm{~min})$ as a gross estimate of their performance. Finally, the recognition memory test was presented on the same laptop computer, with negative and neutral words (as well as old and new words) presented in pseudorandom order. As each word appeared on the screen, participants were asked to indicate "spontaneously, without much deliberation" whether they had seen the word earlier in the learning phase. Participants were free to enter the responses by themselves, on their keyboards, or have the experimenter enter their responses for them on a separate keyboard. Words remained on the screen until a response was given.

\section{Data Analysis}

Correct recognition (hit) rates and false recognition (false alarm) rates were determined for negative and neutral items and subjected to two-high-threshold analysis (Snodgrass \& Corwin, 1988) yielding $P_{\mathrm{r}}$ for accurate recognition memory performance and $B_{\mathrm{r}}$ for the bias toward responding "old." Group comparisons were made using
$2 \times 2$ ANOVAs with repeated measures for emotional valence. The EIRB was quantified as the difference in $B_{\mathrm{r}}$ between negative and neutral items. The TMT Executive Score (TMT-B minus TMT-A) was determined; a higher score indicates reduced executive control. One patient (ID No. 5) did not perform on the TMT; he was excluded from the correlation analysis and the scatterplot, but was kept in the analyses of group differences.

\section{RESULTS}

Despite the matching of the groups for age and education, the TMT executive scores of the patients $(M=220$, $S D=175.15)$ were clearly higher than those of the healthy participants $(M=62.79, S D=29.98)[t(48)=4.775, p<$ $.001]$, albeit with some overlap, mostly due to the elderly individuals in the healthy sample (see Figure 1B).

The valence ratings of the words showed a significant effect of emotional valence $[F(1,48)=741.49, p<.001]$ with no significant effect of group $[F(1,48)=0.46, p=$ 
$.50]$ and only a marginally significant interaction of group $\times$ valence $[F(1,48)=3.26, p<.10]$. The latter was due to the fact that the patients showed a slightly larger difference between neutral and negative words.

The ANOVA of the bias measure $B_{\mathrm{r}}$ showed, as expected, a highly significant effect of emotional valence, reflecting a strong EIRB $[F(1,48)=26.99, p<.001]$. The main effect of group was marginally significant, as the patients tended toward a more conservative bias (lower $B_{\mathrm{r}}$ ); that is, they responded "no" (i.e., "new") more often, presumably because they were more uncertain about their memory than were the healthy participants $[F(1,48)=3.25, p<.10]$. Crucially, however, the EIRB was intact in both groups, as indicated by a significant difference in the bias $\left(B_{\mathrm{r}}\right)$ between negative and neutral words in both the healthy participants $[t(27)=$ 4.07, $p<.001]$ and the patient group $[t(21)=3.48, p<$ $.001]$, with no significant group $\times$ valence interaction $[F(1,48)=0.54, p=.46]($ see Figure $1 \mathrm{~A})$.

The measure $P_{\mathrm{r}}$ for accurate memory showed a significant effect of emotional valence $[F(1,49)=6.33$, $p<.05$ ], indicating higher memory accuracy for negative words than for neutral words. Not surprisingly, there was also a highly significant effect of group $[F(1,49)=$ $11.53, p<.002]$, reflecting the higher overall recognition performance of the healthy participants compared with the patients (see Figure 1A). The interaction of valence $X$ group was not significant $[F(1,48)=0.004]$.

Across all participants, the TMT executive score did not correlate with the EIRB, that is, with the difference between $B_{\mathrm{r}}$ for negative and $B_{\mathrm{r}}$ for neutral words ( $r=$ $-.047, N=49, p=.748$; see Figure 1B). The EIRB was also only very weakly (and not significantly) correlated with recognition performance in terms of $P_{\mathrm{r}}(r=.174$, $N=49, p=.23$ ).

To empirically determine the semantic structure of the word lists used in this experiment, we performed a post hoc study in which we asked 18 healthy participants ( 10 students of psychology with a mean age of 25 years) to sort the test words into semantic categories to check how well the words were matched for semantic cohesion. The study revealed that the two lists were not matched: On average, participants sorted the negative words into 4.22 categories $(S D=1.98)$ and the neutral words into 5.88 categories $(S D=2.19)[t(17)=3.14$, $p<.01]$, indicating that the negative words were perceived as semantically more interrelated than the neutral words.

\section{DISCUSSION}

The present study investigated a decision-based account of the emotion-induced recognition bias - namely, the hypothesis that the bias results from shifts in executively controlled decision criteria that are flexibly adapted to the affective meaning of the test items. We reasoned that this function would be better performed by individuals with normal executive control performance than by individuals with impaired executive control functions. To test the relevant subfunction of executive control, we used the TMT that requires flexible shifting between two response criteria (letters and numbers). Our results did indeed confirm that the bias to designate a word as "old" was significantly higher for affectively negative test items than for neutral items. Contrary to our hypothesis, however, this difference was fully intact in patients with executive control deficits, although these individuals showed reduced overall memory performance and a more conservative decision bias overall. Specifically, the correlation analysis revealed no indication whatsoever that the EIRB depends on the types of attentional set-shifting, criterion-setting, and response-monitoring processes that are assessed by the TMT.

From our own theoretical point of view (e.g., Windmann $\&$ Kutas, 2001), the result was unexpected; but, due to the enormous variation we had in the TMT scores as well as in the EIRB (which, in fact, was highly significant), we consider it very unlikely to be a Type II error. Both patients and healthy participants had no difficulty understanding the task instructions, and they generally behaved as expected. The data pattern was highly robust against exclusion of selected cases, for example, of patients who had not been able to complete the TMT-B, or of patients whose TMT scores fell within the range of the control group. If the latter patients were excluded, the TMT scores (indicating reduced executive control) of the remaining patients were positively correlated with the EIRB (see Figure 1B), contrary to what would have been expected from the executive control account of the EIRB. When patient and control participants were considered separately, correlations were around zero for both groups (see Figure 1B), which essentially reflects a replication of a null result in an independent sample. Furthermore, even if one doubts the validity of the TMT executive score as determined here, or the use of the TMT as a relevant measure of executive control, it was clear from additional neuropsychological testing (see sample description in Table 1), as well as from unstandardized clinical observations, that the patients had serious deficiencies in various forms of executive control functions, yet they showed a fully intact EIRB. We therefore conclude that executive control is unlikely to account for significant interindividual variability in the EIRB, at least in the form of attentional set shifting.

Alternative accounts of the EIRB have attributed the phenomenon to automatic, bottom-up signals arising during retrieval of emotional and neutral words. There are two theories of this sort. The first one relates the EIRB to the effects of semantic cohesion in proposing that emotionally negative words may be semantically more interrelated than emotionally neutral words (Maratos et al., 2000; but see Johansson et al., 2004; McNeely et al., 2004), as confirmed by our own post hoc study. Due to stronger priming effects and other mechanisms that are not yet fully understood, this enhanced interrelatedness drives up hit and false alarm rates, resulting in a more liberal response bias, similar to what has been observed in the Deese/Roediger-McDermott (DRM) paradigm (Miller \& Wolford, 1999; Roediger \& McDermott, 1995). 
The second theory holds the effects of emotional arousal on cognitive attributions during memory retrieval processes responsible for the EIRB. Limbic regions, in particular the amygdala, are highly sensitive to affective cues and respond by boosting activity in perceptual areas, the hippocampus complex, and the orbitofrontal cortex, among other effects. These processes may enhance feelings of subjective saliency, clarity, and vividness, which can be misattributed as reflections of familiarity during ongoing memory retrieval (Phaf \& Rotteveel, 2005; Sharot, Delgado, \& Phelps, 2004; Windmann \& Krüger, 1998). According to this interpretation, the EIRB is a memory illusion that drives participants to respond "old," despite unchanged decision criteria. Phenomena of this sort seem to be facilitated by unconscious (relative to conscious) stimulus processing (Garcia-Marques, Mackie, Claypool, \& Garcia-Marques, 2004; Goldinger \& Hansen, 2005; Jacoby \& Whitehouse, 1989; Phaf \& Rotteveel, 2005).

At present, we are unable to decide between these two alternative theories, especially since our word lists were not matched for semantic cohesiveness. In fact, no prior study has demonstrated the EIRB with word lists that were matched on the basis of sorting studies - a crucial requirement, in our view. However, we find the second explanation, referring to the misattribution of emotional arousal, more consistent than the semantic cohesion account with the present data, because previous studies with amnesiac patients and the DRM paradigm suggest that effects of semantic cohesion should covary with veridical memory performance (Koutstaal, Verfaellie, \& Schacter, 2001; Schacter, Verfaellie, Anes, \& Racine, 1998). In the present study, there was no evidence that the EIRB correlated with accurate memory, despite the wide variations in the performance scores from - 10 (chance performance) to 1 (perfect memory). Other, more direct tests of the semantic cohesion account have not found supporting evidence either (Johansson et al., 2004; McNeely et al., 2004), although inconsistencies remain (Windmann \& Chmielewski, 2006).

Contrary to memory performance, affect-related functions were fully intact in our patients, who, in fact, showed no impairments whatsoever in their ability to evaluate and classify the words according to emotional meaning (with the caveat, of course, that no physiological reactions were taken). Considering these factors, we therefore suggest that automatic, bottom-up interactions between affect- and retrieval-related processes are more responsible for the EIRB than accurate memory or attentional set-shifting functions, both of which seem more dependent on strategically controlled top-down processes. The finding that patients with dysfunctional affect (panic and depression) showed reduced electrophysiological and reduced behavioral correlates of the EIRB (Windmann \& Krüger, 1998; Windmann, Sakhavat, \& Kutas, 2002) provides further support for this notion. However, we note that further testing is needed, particularly to distinguish between different kinds of bottom-up accounts, and we hope that the present findings will stimulate research on the nature and the origin of the emotion-induced recognition bias, in addition to providing empirical constraints for existing theories.

\section{REFERENCES}

Anderson, M. C., Ochsner, K. N., Kuhl, B., Cooper, J., Robertson, E., Gabrieli, S. W., et AL. (2004). Neural systems underlying the suppression of unwanted memories. Science, 303, 232235.

ANDRÉs, P. (2003). Frontal cortex as the central executive of working memory: Time to revise our view. Cortex, 39, 871-895.

Bartholow, B. D., DickTer, C. L., \& SeStiR, M. A. (2006). Stereotype activation and control of race bias: Cognitive control of inhibition and its impairment by alcohol. Journal of Personality \& Social Psychology, 90, 272-287.

Bechara, A., Tranel, D., \& Damasio, H. (2000). Characterization of the decision-making deficit of patients with ventromedial prefrontal cortex lesions. Brain, 123, 2189-2202.

Benton, A. L., \& HAMSHER, K. (1976). Multilingual aphasia examination manual. Iowa City: University of Iowa.

Ble, A., Volpato, S., Zuliani, G., Guralnik, J. M., Bandinelli, S., Lauretani, F., ET AL. (2005). Executive function correlates with walking persons: The InCHIANTI study. Journal of the American Geriatric Society, 53, 410-415.

DoLAN, R. J. (2002). Emotion, cognition, and behavior. Science, 298, 1191-1194.

Drane, D. L., Yuspeh, R. L., Huthwaite, J. S., \& Klingler, L. K. (2002). Demographic characteristics and normative observations for derived-trail making test indices. Neuropsychiatry, Neuropsychology, \& Behavioral Neurology, 15, 39-43.

DRÜHE-WIENHOLT, C. M., \& WiENHOLt, W. (1998). Computergestütztes Kartensortier-verfahren [Computer-based Card Sorting Test]. Frankfurt am Main: Swets.

Garcia-Marques, T., Mackie, D. M., Claypool, H. M., \& GarciaMarques, L. (2004). Positivity can cue familiarity. Personality \& Social Psychology Bulletin, 30, 585-593.

Goldinger, S. D., \& HANSEN, W. A. (2005). Remembering by the seat of your pants. Psychological Science, 16, 525-529.

Henson, R. N., RugG, M. D., Shallice, T., \& Dolan, R. J. (2000). Confidence in recognition memory for words: Dissociating right prefrontal roles in episodic retrieval. Journal of Cognitive Neuroscience, 12, 913-923.

HEYDER, K., Suchan, B., \& Daum, I. (2004). Cortico-subcortical contributions to executive control. Acta Psychologica, 115, 271-289.

JACOBY, L. L., \& Whitehouse, K. (1989). An illusion of memory: False recognition influenced by unconscious perception. Journal of Experimental Psychology: General, 118, 126-135.

JoHANSSON, M., MeCKLINGER, A., \& TREESE, A. C. (2004). Recognition memory for emotional and neutral faces: An event-related potential study. Journal of Cognitive Neuroscience, 16, 1840-1853.

Kawasaki, H., Adolphs, R., Kaufman, O., Damasio, H., Damasio, A. R., Granner, M., ET AL. (2001). Single-neuron responses to emotional stimuli recorded in human ventral prefrontal cortex. Nature Neuroscience, 4, 15-16.

KoutstaAl, W., Verfaellie, M., \& Schacter, D. L. (2001). Recognizing identical versus similar categorically related common objects: Further evidence for degraded gist representations in amnesia. $\mathrm{Neu}$ ropsychology, 15, 268-289.

MaRATOS, E. J., Allan, K., \& RugG, M. D. (2000). Recognition memory for emotionally negative and neutral words: An ERP study. $\mathrm{Neu}$ ropsychologia, 38, 1452-1465.

MAREN, S. (2005). Building and burying fear memories in the brain. Neuroscientist, 11, 89-99.

MATTHEWS, G., \& WELLS, A. (2000). Attention, automaticity, and affective disorder. Behavior Modification, 24, 69-93.

McGaugh, J. (2003). Memory and emotion: The making of lasting memories. New York: Columbia University Press.

McNeely, H. E., Dywan, J., \& Segalowitz, S. J. (2004). ERP indices of emotionality and semantic cohesiveness during recognition judgments. Psychophysiology, 41, 117-129. 
Miller, M. B., Handy, T. C., Cutler, J., Inati, S., \& Wolford, G. L. (2001). Brain activations associated with shifts in response criterion on a recognition test. Canadian Journal of Experimental Psychology, 55, 162-173.

Míller, M. B., \& Wolford, G. L. (1999). Theoretical commentary: The role of criterion shift in false memory. Psychological Review, 106, 398-405.

Newman, J. P., Wallace, J. F., Strauman, T. J., Skolaski, R. L., Oreland, K. M., MatteK, P. W., ET AL. (1993). Effects of motivationally significant stimuli on the regulation of dominant responses. Journal of Personality \& Social Psychology, 65, 165-175.

O'Doherty, J. P., Critchley, H, Deichmann, R., \& Dolan, R. J. (2003). Dissociating valence of outcome from behavioral control in human orbital and ventral prefrontal cortices. Journal of Neuroscience, 23, 7931-7939.

PHAF, R. H., \& RotTEVEel, M. (2005). Affective modulation of recognition bias. Emotion, 5, 309-318.

Phelps, E. A. (2004). Human emotion and memory: Interactions of the amygdala and hippocampal complex. Current Opinion in Neurobiology, 14, 198-202.

REITAN, R. M. (1992). Trail making test: Manual for administration and scoring. Tucson, AZ: Reitan Neuropsychology Laboratory.

RoEdiger, H., \& McDermott, K. B. (1995). Creating false memories: Remembering words not presented in lists. Journal of Experimental Psychology: Learning, Memory, \& Cognition, 21, 803-814.

Sami, N., Carte, E. T., HinshaW, S. P., \& Zupan, B. A. (2003). Performance of girls with ADHD and comparison girls on the ReyOsterrieth complex figure: Evidence for executive processing deficits. Child Neuropsychology, 9, 237-254.

Schacter, D. L., Verfaellie, M., ANes, M. D., \& Racine, C. (1998). When true recognition suppresses false recognition: Evidence from amnesic patients. Journal of Cognitive Neuroscience, 10, 668-679.

SCHNIDER, A., \& PTAK, R. (1999). Spontaneous confabulators fail to suppress currently irrelevant memory traces. Nature Neuroscience, 2, 677-681.

Sharot, T., Delgado, M. R., \& Phelps, E. A. (2004). How emotion enhances the feeling of remembering. Nature Neuroscience, 7, 1376-1380.

Snodgrass, J. G., \& Corwin, J. (1988). Pragmatics of recognition memory: Applications to dementia and amnesia. Journal of Experimental Psychology: General, 117, 34-50.

Sylvester, C. Y., Wager, T. D., Lacey, S. C., Hernandez, L., Nichols, T. E., Smith, E. E., \& Jonides, J. (2003). Switching attention and resolving interference: fMRI measures of executive functions. Neuropsychologia, 41, 357-370.

Von Cramon, D. Y., Matthes-von Cramon, G., \& Mai, N. (1991). Problem-solving deficits in brain-injured patients: A therapeutic approach. Neuropsychological Rehabilitation, 1, 45-64.

Watanabe, K., Ogino, T., NaKano, K., Hattori, J., Kado, Y., Sanada, S., \& Ohtsuka, Y. (2005). The Rey-Osterrieth complex figure as a measure of executive function in childhood. Brain Development, 27, 564-569.
WeCHSLER, D. (2001). Wechsler Memory Scale (3rd ed.). Göttingen, Germany: Hogrefe.

Windmann, S., \& ChMielewski, A. (in press). Emotion-induced modulation of recognition memory: Memory bias or response bias? Cognition \& Emotion.

Windmann, S., Daum, I., \& GÜNTÜRKÜN, O. (2002). Dissociating prelexical and postlexical processing of affective information in the two hemispheres: Effects of the stimulus presentation format. Brain \& Language, 80, 269-286.

WINDMANN, S., \& KRÜGER, T. (1998). Subconscious detection of threat as reflected by an enhanced response bias. Consciousness \& Cognition, 7, 603-633.

WINDMANN, S., \& KuTAS, M. (2001). Electrophysiological correlates of emotion-induced recognition bias. Journal of Cognitive Neuroscience, 13, 577-592.

WINDMANN, S., SAKHAVAT, Z., \& KuTAS, M. (2002). Electrophysical evidence reveals affective evaluation deficits early in stimulus processing in patients with panic disorder. Journal of Abnormal Psychology, 111, 357-369.

WINDMANN, S., Urbach, T., \& Kutas, M. (2002). Cognitive and neural mechanisms of decision biases in recognition memory. Cerebral Cortex, 12, 808-817.

\begin{tabular}{|c|c|c|c|}
\hline \multicolumn{4}{|c|}{$\begin{array}{c}\text { APPENDIX } \\
\text { Word List }\end{array}$} \\
\hline \multicolumn{2}{|c|}{ Neutral Words } & \multicolumn{2}{|c|}{ Negative Words } \\
\hline imprint & publication & horror & murderer \\
\hline drawing & sketch & massacre & suffering \\
\hline figure & graphics & agony & fright \\
\hline file & aspect & appal & inflammation \\
\hline folder & reading & despair & catastrophe \\
\hline contents & composition & purulence & manslaughter \\
\hline index & rubric & evil & accident \\
\hline fact & function & cadaver & infection \\
\hline argument & thesis & atrocities & attack \\
\hline conversation & motive & epidemic & wound \\
\hline dialogue & standpoint & sorrow & scar \\
\hline poll & accessories & crime & fear \\
\hline survey & symbol & culprit & pain \\
\hline attitude & status & shock & calamity \\
\hline conference & meeting & terror & obsession \\
\hline
\end{tabular}

(Manuscript received July 24, 2005; revision accepted for publication June 14, 2006.) 